\title{
Complete heart block due to disseminated vulval carcinoma
}

\author{
M. M. Htoo and M. A. Nanton \\ From the Regional Cardiac Unit, Papworth Hospital, Cambridge
}

A 70-year-old woman with known malignancy of the vulva developed complete heart block five months after successful radical resection of the tumour. Temporary endocardial pacing was necessary in view of an AdamsStokes attack. Widespread involvement of the myocardium with metastases was the cause of her heart block and subsequent demise.

Although dysrhythmias are common clinical manifestations of cardiac tumours, complete heart block due to neoplasm has rarely been reported since Rösler first described it in 1924. The present report describes a patient with complete heart block due to cardiac metastases from a squamous cell carcinoma of the vulva.

\section{Case report}

A 70-year-old woman underwent vulvectomy for poorly differentiated squamous celled carcinoma in February 1972. The postoperative course was satisfactory and she remained well until the early part of June. She then suffered an attack of unconsciousness and was readmitted to the general hospital.

On examination there, she was lucid with no neurological deficit. There was no clinical evidence of anaemia, lymphadenopathy, or recurrence of the carcinoma. Right brachial blood pressure was $170 / 65 \mathrm{mmHg}$ and the heart rate 54/minute with regular rhythm. Jugular venous pressure was raised about $7 \mathrm{~cm}$ above the sternal angle. Bilateral ankle oedema was detected and the liver was palpable. The apex beat was displaced outside the midclavicular line in the fifth interspace. Heart sounds were normal and there was a grade $\mathrm{r} / 4$ ejection murmur in the aortic area. The electrocardiogram showed complete heart block with an idioventricular rate of $50 /$ minute (Fig. r). Chest $x$-ray disclosed no bony or soft tissue metastases but her heart was enlarged and the upper lobe veins were dilated. Her failure was treated with diuretics and a pacing electrode passed via the right subclavian vein into the right ventricle. Satisfactory pacing was initiated at $70 /$ minute.

She had no further attacks of unconsciousness and her heart failure improved. She was then transferred to this unit for consideration of the need for a permanent pacing system.
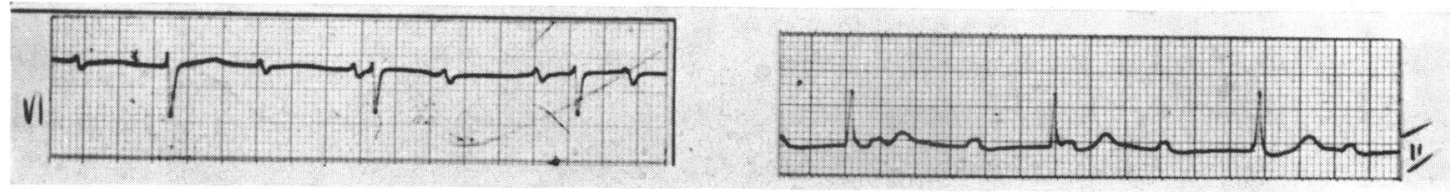

FIG. I Leads VI and II showing complete heart block with an idioventricular rate of 5o/minute.
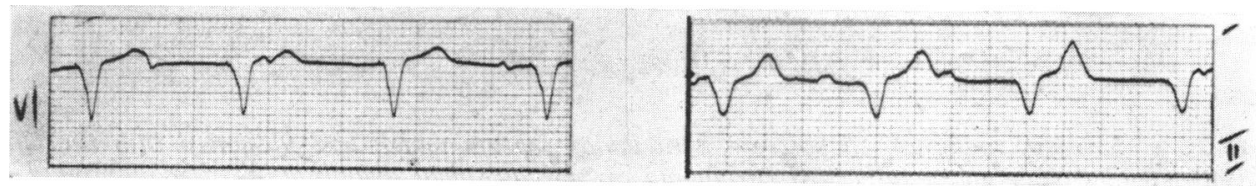

FIG. 2 Satisfactory pacing with temporary endocardial system at 75/minute 
FIG. 3 Upper: malignant deposit on ventricular septum which had ulcerated into the left ventricle. Lower: squamous celled carcinoma on microscopical examination of malignant deposit $(s)$.

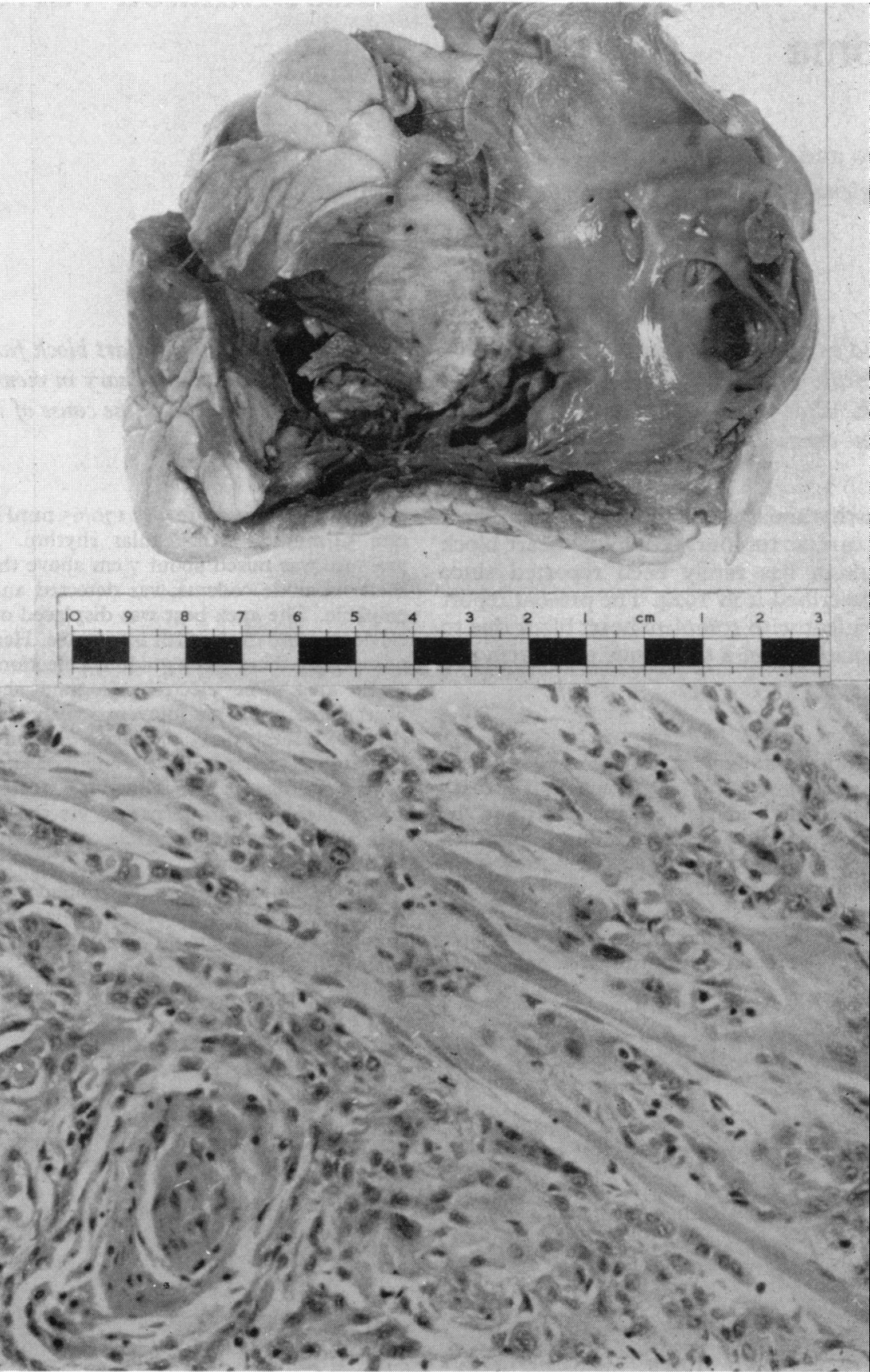


On arrival, there was no evidence of heart failure, right brachial blood pressure was $160 / 70 \mathrm{mmHg}$, and pacing was satisfactory (Fig. 2). Chest $x$-ray showed the pacing electrode tip to be well positioned and the lung fields were clear. Haemoglobin was $13.4 \mathrm{~g} / 100 \mathrm{ml}$; white cell count, blood sedimentation rate, blood urea and electrolytes, were all normal. A gynaecologist gave a good prognosis and found no contraindication to permanent pacing. Unfortunately, towards the end of June she became confused and disorientated and in the process extracted the temporary electrode from her neck. Pacing was reestablished using the left subclavian venous route. Despite this, her mental state failed to improve and she steadily deteriorated. Five days later she had minimal neck stiffness but no localizing or lateralizing neurological signs were elicited. Cerebrospinal fluid was normal. A neurologist felt her confusion was of 'toxic' origin. She died early in July.

\section{Necropsy findings}

A plaque of malignant tissue was situated in the centre of the posterior surface of the right pleura but did not involve the lung. There was a spreading plaque of malignant tissue on the pleura at the apex of the left lung involving the lung to a depth of $2 \mathrm{~mm}$. The heart weighed $320 \mathrm{~g}$ and there was an area of injection over the posterior surface at the level of the AV groove on the right side. The coronary arteries appeared normal. The pacemaker electrode tip was abutting on a malignant deposit $2 \mathrm{~cm}$ in diameter which occupied the apex of the right ventricle. The groove between the right atrium and ventricle was occupied by a large malignant deposit (Fig. 3). Numerous small subendocardial deposits were present in the right atrium. In particular, a deposit $I \times 2 \mathrm{~mm}$ on the septum had ulcerated into the left ventricle. Peritoneal seedlings were present. The brain was not oedematous and appeared normal.

\section{Discussion}

Complete heart block may be caused by local deposits of leukaemic tissue, lymphangioendothelioma, haemangioendothelioma, myeloblastoma, and reticulum celled sarcoma (Yater, 193I). It has recently been reported to be caused by bronchogenic carcinoma with metastases (Buckberg and Fowler, 196I). Other tumours which have been implicated include breast carcinoma and malignant melanoma. The necropsy findings in the case reported here indicate that primary vulval carcinoma may also metastasize to the myocardium and produce heart block.

In most cases of cardiac metastasis, the right atrium is involved (Auerbach, Epstein, and Gold, 1936) and this was so here. Congestive heart failure and cardiac dysrhythmia in the presence of known malignancy, as in this patient, must raise a suspicion of myocardial metastasis.

We are indebted to Drs. D. W. Evans, P. G. I. Stovin, and S. W. B. Newsom for help in preparing this report.

\section{References}

Auerbach, O., Epstein, H., and Gold, H. (1936). Metastatic carcinoma of the heart. American Heart fournal, 12, 467.

Buckberg, G. D., and Fowler, N. O. (196I). Complete atrioventricular block due to cardiac metastasis of bronchogenic carcinoma. Circulation, 24, 657.

Rösler, O. A. (1924). Vier seltenere Herzbefunde: Ein Beitrag zur Herzdiagnostik. Zentralblatt für Herz- und Gefässkrankheiten, 16, 261.

Yater, W. M. (193I). Tumors of the heart and pericardium. Pathology, symptomatology and report of 9 cases. Archives of Internal Medicine, 48, 627.

Requests for reprints to Dr. M. M. Htoo, Regional Cardiac Unit, Papworth Hospital, Cambridge $\mathrm{CB}_{3} 8 \mathrm{PZ}$. 